\title{
Carbon Quotas, Subsidies and Engineering Machinery Remanufacturing
}

\begin{abstract}
Engineering machinery manufacturing and remanufacturing are significant sources of greenhouse gases. In the context of emission reduction and resource recovery, the authors analyze the impact of current carbon quota allocations and government subsidies policies on manufacturers' profits and recovery rates in a closed-loop supply chain. A simplified model consists of two manufacturers, one retailer and a third-party recycler. The study found that carbon quotas and government subsidies can both promote the improvement of recovery rates under certain conditions, and have similar effects in regulating interest distribution between manufacturers. The combination of the two methods can effectively realize the targets of recycling and carbon emissions reduction.
\end{abstract}

Keywords: competitive closed-loop supply chain, government subsidies, carbon quota allocation, remanufacturing

\section{Introduction}

In order to achieve a sustainable development, a consensus on building a resource-conserving and environmentfriendly society needs to be reached (Chen \& Zhou, 2014; Zheng, Zheng, Chen, \& Lu, 2014). A supply chain in which forward and reverse supply chain activities are integrated is referred to as closed-loop supply chain (Guide \& Van Wassenhove, 2009). A closed-loop supply chain (CLSC) shows a good performance in improving the environment (Amezquita, Hammond, Salazar, \& Bras,

Manuscript received September 15, 2015; accepted January 1, 2016

Dong-bin $\mathrm{Hu}(\bowtie)$, Chen-xi Xiao

Business School, Central South University, Changsha 410083, China; Collaborative Innovation Center of Resource-conserving \& Environment-friendly Society and Ecological Civilization, Changsha 410083,

China

Email: hdbin@163.com

Xiao-hong Chen

Business School, Central South University, Changsha 410083, China; Collaborative Innovation Center of Resource-conserving \& Environment-friendly Society and Ecological Civilization, Changsha 410083, China; Hunan University of Commerce, Changsha 410205, China
1995; Giutini \& Gaudette, 2003; Guide \& Van Wassenhove, 2009). In order to protect the environment and improve the utilization efficiency of resources, the government would take some measures to promote the development of CLSC. There is plenty of literature about the government rules' impact on the closed-loop supply chain. For example, the government should provide incentives to reduce the cost of manufacturing and improve the percentage of remanufacturing (Majumder \& Groenevelt, 2001; Mitra \& Webster, 2008). There is some research about the effect of government rewards and punishment mechanisms on the recovery rate and price in closed-loop supply chains (Guan, Zhou, \& Cao, 2009; Wang \& Da, 2011; Xiong, Huang, \& Xiong, 2011).

With global warming becoming an important environmental problem that the world faces, government agencies across the world are under growing pressure to limit the amount of greenhouse gas emissions. Carbon cap-andtrade (CCT) as a way of marketization has already become an important tool and mainstream means in reducing carbon emissions (Montgomery, 1972; Stavins, 2008; Zeng $\&$ Wan, 2010). The CCT-mechanism means a quota of carbon emission (carbon cap) is allocated to a firm by an external regulatory body and the firm can buy or sell carbon credit on a trading market of carbon emissions (Bird, Holt, \& Levenstein Carroll, 2008). With the establishment of the national carbon trading market in 2016, the CCT-mechanism will play an important role in reducing carbon emissions in China.

Machinery engineering manufacturing and remanufacturing are a significant source of greenhouse gases. According to related research, the result shows that, due to the presence of market power and transaction costs, the initial allocation of emission rights will affect the configuration of the market and the subject's benefits (Cason, 2003). It can be predicted that the CCT-mechanism of carbon emission constraint will make it costly to emit carbon. As a result, the government should use it properly to reducing carbon emission, but avoid the negative impact of carbon emission constraint on engineering machinery recovery and remanufacturing in the meantime. Therefore, a remanufacturing closed-loop supply chain under carbon 
emission constraint has received increasing attention: Such as carbon emissions influence on earnings volatility in a CLSC (Gao, Hou, Wang, \& Han, 2015), the impact of carbon quota charges on the manufacturers in a closed-loop supply chain ( $\mathrm{Li}, \mathrm{Du}$, Yang, \& Hua, 2014) and the production decision problem of one manufacturer in a two production cycle under a carbon cap-and-trade scenario (Chang, Xia, Zhu, Fan, \& Zhao, 2015). Research above has great value of reference, but most of the study is based on a single manufacturer. In reality, it is rare that there is only one manufacturer as a monopolist in an industry, while competition is widespread. In order to gain a competitive edge, the behavior of the enterprise is affected not only by government policy, but also by rival behavior (Heese, Cattani, Ferrer, Gilland, \& Roth, 2005).

The main objective of this paper is to study a singleperiod supply chain model under the CCT-mechanism of carbon emission constraint, including the competition between two manufacturers. Manufacturer 1 not only produces new products but recycles to remanufacture while Manufacturer 2 produces new products only. The authors will also analyze how to avoid the negative impact caused by carbon emission constraints on engineering machinery recovery and remanufacturing. Our model also includes a retailer and a third-party recycler.

Although three models of recovery were studied, finding the retailer's recycle is most effective (Savaskan, Bhattacharya, \& Van Wassenhove, 2004). Because of the uncertainty of the recycling quality, there is an uncertainty of reusable components and the efficiency of the recovery model varies (Gao, Hou, Wang, \& Han, 2015). Taking China's current situation into account that recycling by manufacturers and retailers is not so popular, the authors look at a third-party recovery in this paper, as shown in Figure 1.

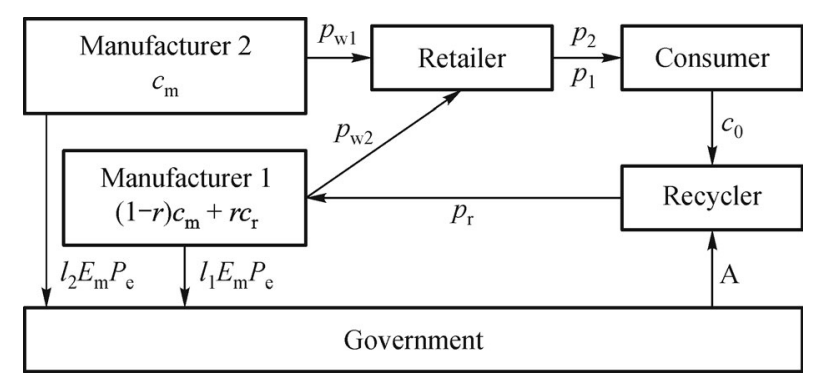

Figure 1. Closed-loop supply chain based on government subsidies and the distribution of carbon quotas.

The paper is organized as follows: Section 2 describes the problem and assumptions; Section 3 presents models and solutions; in Section 4 the impacts of CCT-mechanism and subsidies are analyzed by theoretical and numerical analysis; comparisons and main conclusions are drawn in Section 5 .

\section{Problem statements and assumptions}

Assumption 1. Suppose all the engineering machinery products produced by two manufacturers can be regarded the same. The manufacturers can not only fully use raw materials for production, also can partly use recycled materials to produce (They can both use raw materials and recycled materials for production.). All the used products can be recycled including other company's products.

Assumption 2. The market is open and the members of closed-loop supply chains know the same information. The demand for engineering machinery products is stable, so the single cycle research has certain representativeness.

Assumption 3. In the model, manufacturers, retailers, and the third-party recycler are independent decision makers. The manufacturer is the leader in the Stackelberg game, the retailer has equal status with the third party, and all of them make decisions in order to maximize their own interests.

Assumption 4. Because technical innovation needs a certain amount of time, the product of the unit of carbon emissions remains relatively stable during a certain time.

The authors think there is a need to give an explanation. Why are there still so many manufacturers who do not want to recycle, even when the new products and remanufactured products are homogeneous? Studies have shown that most of the manufacturers have no infrastructure and expertise to collect used products and remanufacture (Ferguson \& Souza, 2010; Sutherland, Adler, Haapala, \& Kumar, 2008). For these producers, the income gained by remanufacturing is not enough to stimulate them to invest in research and development or adopt recycling technology and put in place a remanufacturing infrastructure. Thus, government regulation is needed to stimulate manufacturers to recycle and then the assumption is relatively reasonable.

In Table 1, the authors list variables of their description and assumptions.

\section{Models}

Based on the notations and assumptions in Table 1, the authors know that, without regard to the CCT-mechanism, the average unit product cost of manufacturer 1 is $c_{\mathrm{m}}\left(1^{-}\right.$ $r)+\left(c_{\mathrm{r}}+p_{\mathrm{r}}\right) r$ while the unit product cost for Manufacturer 2 is $c_{\mathrm{m}}$.

\subsection{No subsidies and carbon emission constraint}

Manufacturer 1 decision function is

$$
V_{\mathrm{m} 1}=\left\{p_{\mathrm{w}}-\left[c_{\mathrm{m}}(1-r)+\left(c_{\mathrm{r}}+p_{\mathrm{r}}\right) r\right]\right\}\left(a-p_{1}+\varepsilon p_{2}\right) \text {. }
$$

Manufacturer 2 decision function is 
Table 1

The Description and Assumptions of Variables

\begin{tabular}{|c|c|}
\hline Variable & Description and assumption \\
\hline$c_{0}$ & Unit recycling product price that the third-party recycler pays to consumers \\
\hline$p_{\mathrm{r}}$ & Unit recycling product price that Manufacturer 1 pays to the third-party recycler, the decision variables for Manufacturer 1 \\
\hline$c_{\mathrm{m}}$ & Unit cost of the new product \\
\hline$c_{\mathrm{r}}$ & Added cost of remanufacturing one product. $c_{r}+c_{0}$ means unit cost of the remanufacturing product \\
\hline$p_{1}, p_{\mathrm{w} 1}$ & $\begin{array}{c}\text { The wholesale price and sales price of product made by Manufacturer } 1, p_{1} \text { is the decision variables for retailers, } p_{\mathrm{w} 1} \text { is the decision } \\
\text { variables for Manufacturer } 1\end{array}$ \\
\hline$p_{2}, p_{\mathrm{w} 2}$ & $\begin{array}{l}\text { The wholesale price and sales price of product made by Manufacturer } 2, p_{2} \text { is the decision variable for retailers, } p_{\mathrm{w} 2} \text { is the decision variable } \\
\text { for Manufacturer } 2\end{array}$ \\
\hline$r$ & The recovery rate, $r(0 \leqslant r \leqslant 1)$ is the decision variable for the third-party recycler \\
\hline$V$ & Profit \\
\hline$l_{1}, l_{2}$ & $\begin{array}{l}\text { The proportion carbon emissions quotas that regulatory body allocate to Manufacturers } 1 \text { and } 2 \text { non-gratuitously. } 0 \leqslant l_{1}, l_{2} \leqslant 1 \text {. For the sake } \\
\text { of analysis, the authors assume } l_{1}=v l_{2}, 0 \leqslant v \leqslant 1 \text {. If } v<1 \text {, it means the government allocates more free quota to Manufacturer } 1\end{array}$ \\
\hline$E_{\mathrm{m}}$ & Carbon emission of unit new product \\
\hline$E_{\mathrm{r}}$ & $\begin{array}{l}\text { Carbon emission of unit remanufacturer product. } E_{\mathrm{r}}=u E_{\mathrm{m}} \text {. Here the authors consider the differences of carbon emissions. } 0 \leqslant u \leqslant 1 \text {, it } \\
\text { means the carbon emissions of remanufactured product is less than a new product. } 1 \leqslant u \leqslant \frac{c_{\mathrm{m}}-c_{0}-c_{\mathrm{r}}}{l_{2} p_{2} E_{\mathrm{m}}}+1 \text { means the carbon emissions of } \\
\text { remanufactured product is more than a new product. When the cost saving is less than the cost of carbon emissions, the remanufacturer will } \\
\text { not recycle. }\end{array}$ \\
\hline$p_{\mathrm{e}}$ & Unit carbon quota price, the price is decided by the market \\
\hline$A$ & Unit recycling product subsidy from the government \\
\hline$Q_{1}, Q_{2}$ & $\begin{array}{l}\text { The sales quantity of products produced by two manufacturers, referring to Debo et al. (2005) and Ferrer and Swaminathan (2006), the } \\
\text { authors suppose } Q_{1}(p)=a-p_{1}+\varepsilon p_{2}, Q_{2}(p)=a-p_{2}+\varepsilon p_{1}, 0<\varepsilon<1 \text {, where } a \text { represents the basic size of the market }\end{array}$ \\
\hline$k$ & Referring to Savaskan et al. (2004), $k$ is the scale parameter \\
\hline
\end{tabular}

$$
V_{\mathrm{m} 2}=\left(p_{\mathrm{w}}-c_{\mathrm{m}}\right)\left(a-p_{2}+\varepsilon p_{1}\right) .
$$

Because the retailer sells products from two manufacturers, determining their own retail price, according to the whole sale price that the two manufacturers give him. Therefore, its total profit equals profit per unit product multiplied by the sales.

$$
V_{\mathrm{r}}=\left(p_{1}-p_{\mathrm{w} 1}\right)\left(a-p_{1}+\varepsilon p_{2}\right)+\left(p_{2}-p_{\mathrm{w} 2}\right)\left(a-p_{2}+\varepsilon p_{1}\right)
$$

Referring to Savaskan et al. (2004), the third-party recycler's profit is the profit per unit of recycled product multiplied by the recycled product quantity, subtracting fixed investment $I, I=k r^{2}$.

$$
V_{3}=r\left(p_{\mathrm{r}}-c_{\mathrm{o}}\right)\left(a-p_{1}+\varepsilon p_{2}\right)-k r^{2}
$$

3.2 The government gives subsidies to the third-party recycler

In this section, the authors consider that the government gives subsidies to the third-party recycler as is common in China today. Subsidies are proportional to the amount recycled.

$$
V_{3}=r\left(p_{\mathrm{r}}-c_{0}\right)\left(a-p_{1}+\varepsilon p_{2}\right)-k r^{2}+r\left(a-p_{1}+\varepsilon p_{2}\right) A .
$$

Other functions remain the same with that in Section 3.1.

\subsection{CCT-mechanism of carbon emission constraint}

In this section, the authors consider that the government will allocate carbon quotas to two manufacturers nongratuitously.

$l_{1}$ and $l_{2}$ represent the proportion of carbon emissions quotas that the regulatory body allocates to Manufacturers 1 and 2 non-gratuitously.

$$
E_{\mathrm{r}}=u E_{\mathrm{m}}, l_{1}=v l_{2} .
$$

And define $\Delta=c_{\mathrm{m}}-c_{\mathrm{r}}$, we have

$$
\begin{aligned}
V_{\mathrm{m} 1}= & {\left[p_{\mathrm{w} 1}-c_{\mathrm{m}}+\left(\Delta-p_{\mathrm{r}}\right) r\right]\left(a-p_{1}+\varepsilon p_{2}\right) } \\
& -v l_{2}\left[r\left(a-p_{1}+\varepsilon p_{2}\right) u E_{\mathrm{m}} p_{\mathrm{e}}\right. \\
& \left.+(1-r)\left(a-p_{1}+\varepsilon p_{2}\right) E_{\mathrm{m}} p_{\mathrm{e}}\right],
\end{aligned}
$$

$$
V_{\mathrm{m} 2}=\left(p_{\mathrm{w} 2}-c_{\mathrm{m}}\right)\left(a-p_{2}+\varepsilon p_{1}\right)-l_{2}\left(a-p_{2}+\varepsilon p_{1}\right) E_{\mathrm{m}} p_{\mathrm{e}} .
$$


Other functions remain the same with that in Section 3.1.

\subsection{Subsidies and carbon emission constraint}

In this section, the authors consider scenarios that combine subsidies and carbon emission constraint. For the sake of simplicity, we do not list the equation here, and the equation set is Eqs. (3), (5), (6), and (7).

Without loss of generality, the authors will use backward induction applied to the equation set above, and the variable's value of Section 3.4 is as shown in Table 2.

Assume $\quad M=-2 c_{0}^{2}+(4 A+4 \Delta) c_{0}-2 A^{2}-4 A \Delta-2 \Delta^{2}$ $+32 k, \Delta=c_{\mathrm{m}}-c_{\mathrm{r}}$.

Let $A=0$ and $l_{2}=0$ in Table 2, one can get the variable's value of Section 3.1;

Let $l_{2}=0$ in Table 2, one can get the variable's value of Section 3.2;

Let $A=0$ in Table 2, one can get the variable's value of Section 3.3.

In order to distinguish the variable's value under different scenarios, the authors will mark in the upper right of the symbol, such as $r^{\mathrm{I}}, r^{\mathrm{II}}, r^{\mathrm{III}}$, and $r^{\mathrm{IV}}$ representing the value of $r$ in Sections 3.1, 3.2, 3.3, and 3.4, respectively.

\section{Analysis}

This section presents an analysis of the models described in
Section 3. Taking into account the subsidies and carbon quota allocation, the authors analyze the impact of them on the products' price, profit of the two manufacturers and recovery rate. Some numerical results are presented to illustrate our theoretical results.

4.1 The government gives subsidies to the third-party recycler

By observing the optimization problem in Section 3.2, it is easy to see the following proposition.

Proposition 1:

(1) The government subsidies have a significant influence on the recovery rate, manufacturers' profit and the whole price of the product;

(2) Government subsidies can increase the recovery rate;

(3) The profit gap between Manufacturers 1 and 2 gradually widens as subsidies increase.

This conclusion is similar to the Mitra and Webster's study (2008). They suggested that the manufacturer's profits generally decrease while the remanufacturer's profits increase as subsidies increase. As a result, the authors think the completeness and accuracy of the model in this paper can be verified to some extent.

Proposition 1 illustrates that subsidies have a great influence on recovery activity. Manufacturers 1 and 2 and the third-party recycler will adjust their production

\section{Table 2}

The Analytical Solutions of Variables

\begin{tabular}{|c|c|}
\hline Variable & Analytical solution \\
\hline$p_{w 1}$ & $\begin{array}{l}\quad\left[2 l_{2} v p_{\mathrm{e}} E_{\mathrm{m}}(u-1)\left(A+\Delta-c_{0}\right)-l_{2}^{2} v^{2} p_{\mathrm{e}}^{2} E_{\mathrm{m}}^{2}(u-1)^{2}\right]\left[\left(l_{2} p_{\mathrm{e}} E_{\mathrm{m}}+a+c_{\mathrm{m}}\right) \varepsilon+2 a\right]+ \\
\frac{\varepsilon+32 v k l_{2} p_{\mathrm{e}} E_{\mathrm{m}}+a M+32 k c_{\mathrm{m}}}{l_{2}^{2} p_{\mathrm{e}}^{2} E_{\mathrm{m}}^{2} v^{2}(u-1)^{2}\left(\varepsilon^{2}-2\right)-2 l_{2} p_{\mathrm{e}} E_{\mathrm{m}} v(u-1)\left(\varepsilon^{2}-2\right)\left(A+\Delta-c_{0}\right)-0.5 M \varepsilon^{2}+M+32 k}\end{array}$ \\
\hline$p_{1}$ & $\frac{(\varepsilon-1) p_{\mathrm{w} 1}-a}{2 \varepsilon-2}$ \\
\hline$p_{w 2}$ & $\begin{array}{c}{\left[2 l_{2} v p_{\mathrm{e}} E_{\mathrm{m}}(u-1)\left(A+\Delta-c_{0}\right)-l_{2}^{2} v^{2} p_{\mathrm{e}}^{2} E_{\mathrm{m}}^{2}(u-1)^{2}\right]\left(l_{2} p_{\mathrm{e}} E_{\mathrm{m}}+a \varepsilon+a+c_{\mathrm{m}}\right)+} \\
\frac{l_{2} p_{\mathrm{e}} E_{\mathrm{m}}(16 v k \varepsilon+0.5 M+16 k)+\left(0.5 a M+16 k c_{\mathrm{m}}\right) \varepsilon+\left(a+c_{\mathrm{m}}\right)(0.5 M+16 k)}{l_{2}^{2} p_{\mathrm{e}}^{2} E_{\mathrm{m}}^{2} v^{2}(u-1)^{2}\left(\varepsilon^{2}-2\right)-2 l_{2} p_{\mathrm{e}} E_{\mathrm{m}} v(u-1)\left(\varepsilon^{2}-2\right)\left(A+\Delta-c_{0}\right)-0.5 M \varepsilon^{2}+M+32 k}\end{array}$ \\
\hline$p_{2}$ & $\frac{(\varepsilon-1) p_{\mathrm{w} 2}-a}{2 \varepsilon-2}$ \\
\hline$p_{r}$ & $\frac{1}{2}\left(-l_{2} p_{\mathrm{e}} E_{\mathrm{m}} v u+l_{2} p_{\mathrm{e}} E_{\mathrm{m}} v-A+\Delta+c_{0}\right)$ \\
\hline$r$ & $\frac{2\left[l_{2} p_{\mathrm{e}} E_{\mathrm{m}}\left(\varepsilon^{2} v+\varepsilon-2 v\right)+(\varepsilon+2)\left(\varepsilon c_{\mathrm{m}}+a-c_{\mathrm{m}}\right)\right]\left[-l_{2} v p_{\mathrm{e}} E_{\mathrm{m}}(u-1)+A+\Delta-c_{0}\right]}{l_{2}^{2} p_{\mathrm{e}}^{2} E_{\mathrm{m}}^{2} v^{2}(u-1)^{2}\left(\varepsilon^{2}-2\right)-2 l_{2} p_{\mathrm{e}} E_{\mathrm{m}} v(u-1)\left(\varepsilon^{2}-2\right)\left(A+\Delta-c_{0}\right)-0.5 M \varepsilon^{2}+M+32 k}$ \\
\hline$V_{\mathrm{m} 1}$ & $\frac{128\left[\left(v l_{2} p_{\mathrm{e}} E_{\mathrm{m}}+c_{\mathrm{m}}\right) \varepsilon^{2}+\left(l_{2} p_{\mathrm{e}} E_{\mathrm{m}}+a+c_{\mathrm{m}}\right) \varepsilon-2 v l_{2} p_{\mathrm{e}} E_{\mathrm{m}}-2 c_{\mathrm{m}}+2 a\right]^{2} k^{2}}{\left[l_{2}^{2} p_{\mathrm{e}}^{2} E_{\mathrm{m}}^{2} v^{2}(u-1)^{2}\left(\varepsilon^{2}-2\right)-2 l_{2} p_{\mathrm{e}} E_{\mathrm{m}} v(u-1)\left(\varepsilon^{2}-2\right)\left(A+\Delta-c_{0}\right)-0.5 M \varepsilon^{2}+M+32 k\right]^{2}}$ \\
\hline$V_{\mathrm{m} 2}$ & $\frac{0.5\left\{\begin{array}{l}l_{2} p_{\mathrm{e}} E_{\mathrm{m}} v(u-1)(\varepsilon+1)\left[l_{2} p_{\mathrm{e}} E_{\mathrm{m}}(\varepsilon-1)+\varepsilon c_{\mathrm{m}}+a-c_{\mathrm{m}}\right]\left[l_{2} p_{\mathrm{e}} E_{\mathrm{m}} v(u+1)-2\left(A+\Delta-c_{0}\right)\right]+ \\
l_{2} p_{\mathrm{e}} E_{\mathrm{m}}\left(-16 k \varepsilon v-0.5 M \varepsilon^{2}+0.5 M+16 k\right)-[0.5 M \varepsilon+0.5 M+16 k]\left(\varepsilon c_{\mathrm{m}}+a-c_{\mathrm{m}}\right)\end{array}\right\}^{2}}{\left[l_{2}^{2} p_{\mathrm{e}}^{2} E_{\mathrm{m}}^{2} v^{2}(u-1)^{2}\left(\varepsilon^{2}-2\right)-2 l_{2} p_{\mathrm{e}} E_{\mathrm{m}} v(u-1)\left(\varepsilon^{2}-2\right)\left(A+\Delta-c_{0}\right)-0.5 M \varepsilon^{2}+M+32 k\right]^{2}}$ \\
\hline$V_{3}$ & $\frac{4 k\left[l_{2} p_{\mathrm{e}} E_{\mathrm{m}}\left(\varepsilon^{2} v+\varepsilon-2 v\right)+(\varepsilon+2)\left(\varepsilon c_{\mathrm{m}}+a-c_{\mathrm{m}}\right)\right]^{2}\left[l_{2} p_{\mathrm{e}} E_{\mathrm{m}} v(u-1)+A+\Delta-c_{0}\right]^{2}}{\left[l_{2}^{2} p_{\mathrm{e}}^{2} E_{\mathrm{m}}^{2} v^{2}(u-1)^{2}\left(\varepsilon^{2}-2\right)-2 l_{2} p_{\mathrm{e}} E_{\mathrm{m}} v(u-1)\left(\varepsilon^{2}-2\right)\left(A+\Delta-c_{0}\right)-0.5 M \varepsilon^{2}+M+32 k\right]^{2}}$ \\
\hline
\end{tabular}


schedule to maximize their profit. Accordingly, the recovery and remanufacturer activity will change correspondingly.

Example1: The authors set $c_{\mathrm{m}}=30, c_{0}=8, c_{\mathrm{r}}=18$, $k=100, a=80, \varepsilon=0.5, E_{\mathrm{m}}=1, p_{\mathrm{e}}=5, \Delta=12, l_{2}=0$ as the parameters to illustrate the results in Proposition 1. The important basis for selecting this set of parameters in this paper is to ensure the authors observe some useful results.

One can observe the conclusion in Proposition 1 in Figure 2. The wholesale and retail prices of Products 1 and 2 are reduced thanks to the subsidies, and the wholesale and retail prices of Product 1 drop more than Product 2. Because of the competition, Manufacturer 1 could gain more of the market share than Manufacturer 2 via a lower price. What is more, the profit of Manufacturer 1 increases while Manufacturer's 2 profit decreases as the government gives subsidies to the recycler, and government subsidies can effectively increase the recovery rate.

\subsection{CCT-mechanism of carbon emission constraint}

\subsubsection{Considering carbon emissions differences}

It is usual that there are carbon emissions differences between new product and remanufactured product, so what is the impact of carbon emission constraint considering the carbon emissions differences?

Proposition 2:

Compared with the scenario of no carbon emissions differences, when remanufacturing product carbon emission is less than the new product, the income gap between Manufacturers 1 and 2 gradually widens and the recovery rate is higher. When remanufacturing product carbon emission is greater than the new product, the income gap becomes smaller and the recovery rate is lower.

\subsubsection{Allocating different quotas to two manufacturers}

In this section, the authors will assume that there are no carbon emissions differences between new product and remanufactured product. Then the authors will analyze the impact if they allocate different quotas to two manufacturers.

Proposition 3:

(1) Carbon quotas charge will reduce the recovery rate, raises the wholesale price and reduce the two manufacturers' profits.

(2) If the government distributes more free-quotas to remanufacturers, the recovery rate will rise. The gap between the two manufacturers' profits widens compared with the scenario of allocating the same carbon quotas to the two manufacturers.

The effect is similar to the government giving subsidies to the third-party recycler.

Example 2: The authors set $c_{\mathrm{m}}=30, c_{0}=8, c_{\mathrm{r}}=18$, $k=100, a=80, \varepsilon=0.5, E_{\mathrm{m}}=1, p_{\mathrm{e}}=5, \Delta=12, A=0$ as the parameters to show the results. The authors vary the value of $l_{2}$.

The government allocated the same free proportion of carbon quotas to two manufacturers $(v=1)$. When the remanufacturing product carbon emission is less than the new product $(u<1)$, the income gap between Manufacturers 1 and 2 gradually widens as the charge proportion increases. When remanufacturing product carbon emission is greater than the new product $(u>1)$, the income gap becomes smaller. When there is no difference in carbon emissions $(u=1)$, the ratio of the two manufacturers' profit remains the same.

Figure 3 also shows whether there are differences in carbon emissions or not, as manufacturer 1 gains more free quota $(v<1)$, the income gap between manufacturer 1 and manufacturer 2 gradually widens, forcing manufacturer 2 to consider investing in remanufacturing equipment and technology. The effect is similar to subsidies to some extent. However it must be noted that the profit of the two manufacturers is decreasing.

As one can see from Figure 4, the wholesale price is rising even though one allocates more free quotas to Manufacturer 1. In order to eliminate its negative effects,

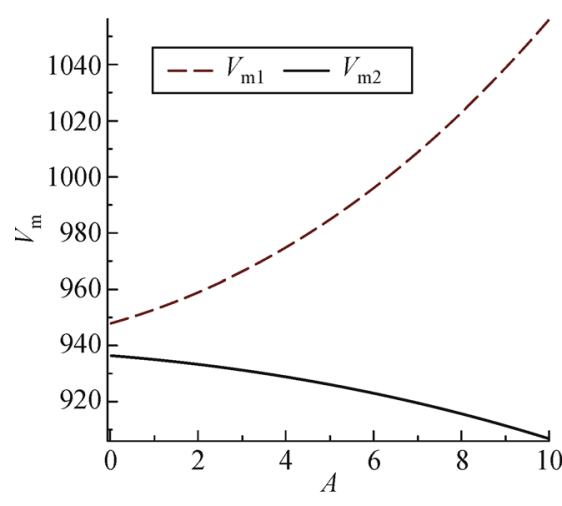

(a)

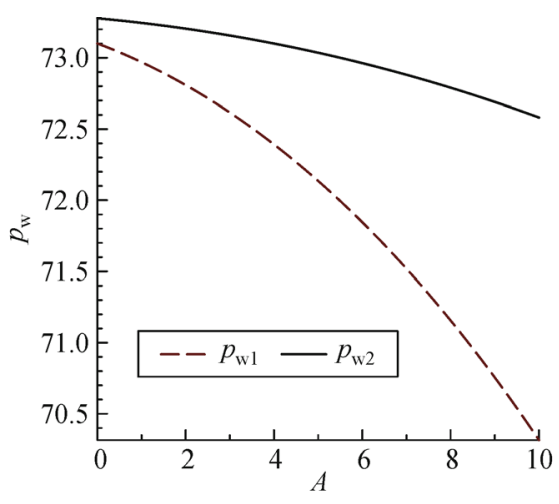

(b)

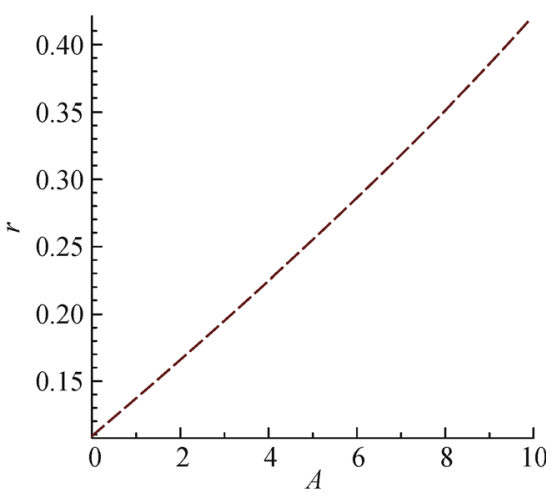

(c)

Figure 2. Impact of subsidies on (a) manufactures' profit, (b) whole price, and (c) recovery rate. 

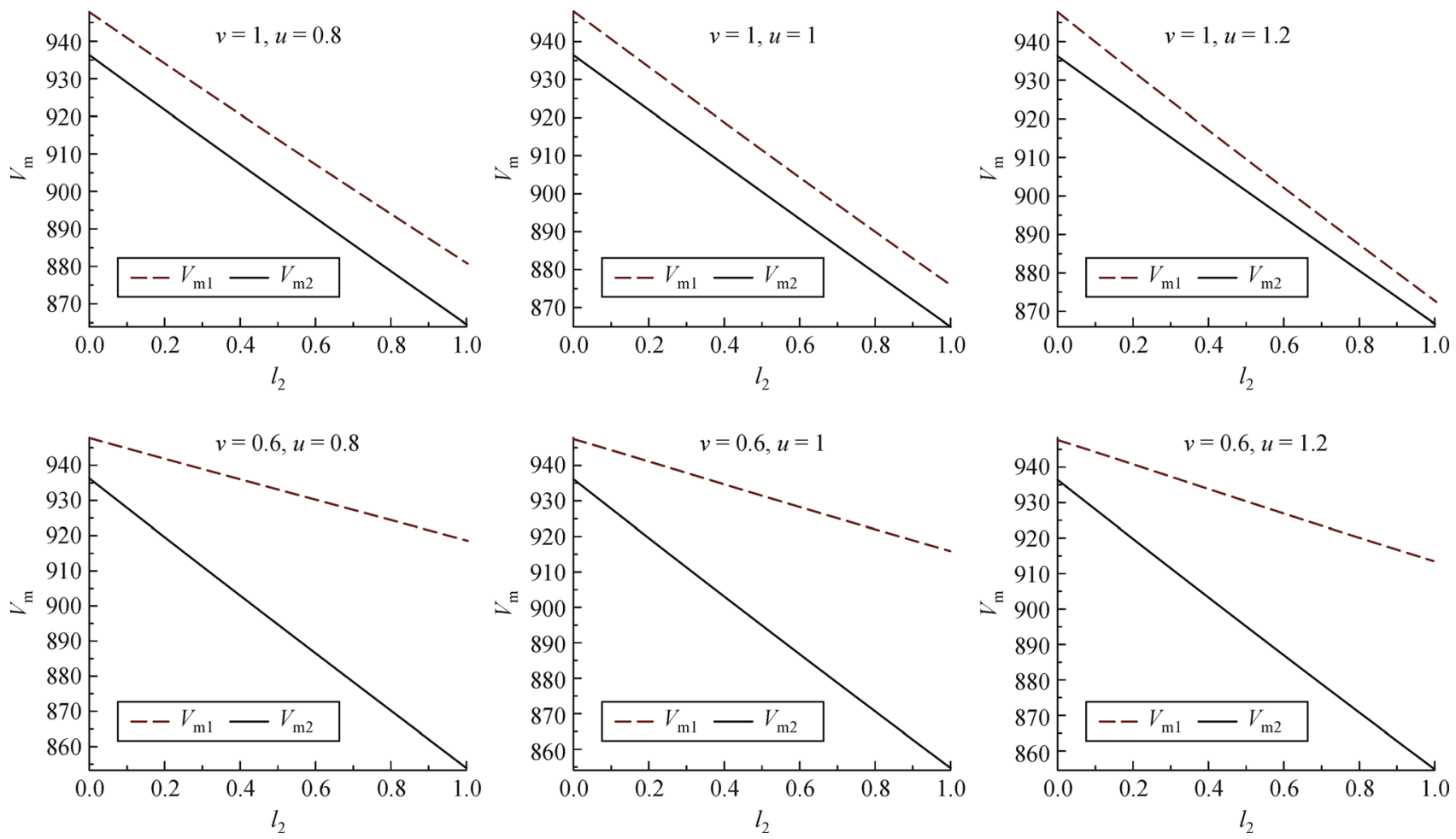

Figure 3. The impact of proportion allocation on two manufacturers' profit.
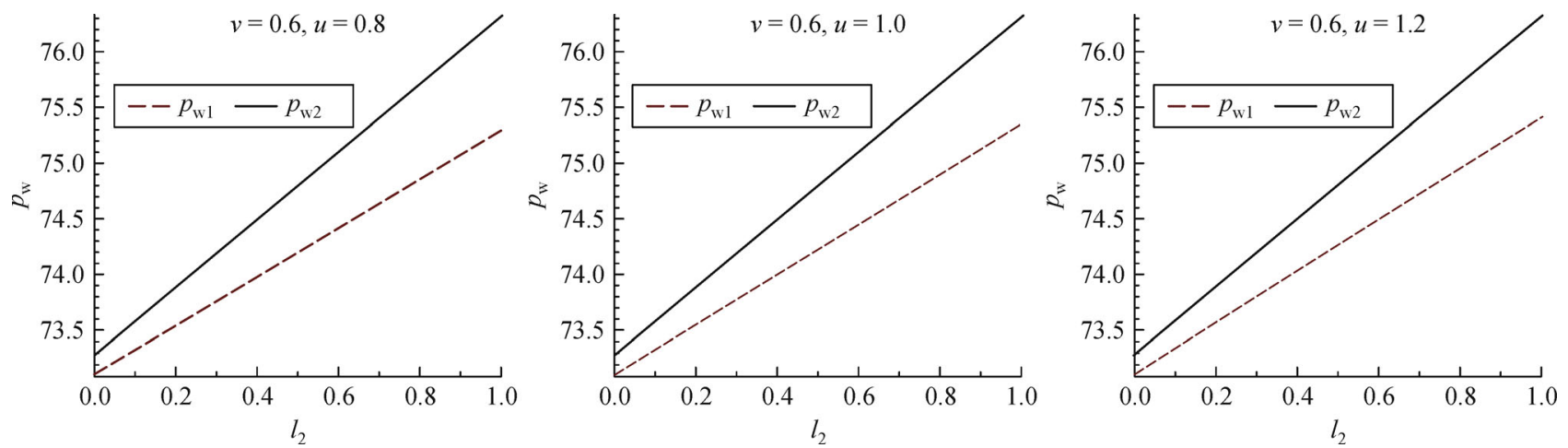

Figure 4. The impact of proportion allocation on manufacturers' wholesale price.

the government subsidies are needed to lower the price which should be controlled in a proper range.

One can learn from the analysis of Figure 5, that when the remanufactured product carbon emission is equal to or more than the new product $(u \geqslant 1)$, the carbon quotas charge will reduce the recovery rate. The government should distribute more free-quotas to remanufacturers to eliminate its negative impact. However, when the remanufactured products' carbon emission is less than the new product $u<1$, the recovery rate is lower if the government distributes more free quotas to remanufacturers. This result of Figure 5 is interesting, but it is easy to understand.

If the proportion of the carbon quotas that the government distributes non-gratuitously to manufacturers is higher, the result is that manufacturers' cost in carbon emissions will increase. In order to reduce the cost of carbon emissions, Manufacturer 1 will increase the proportion of remanufacturing which is helpful to reduce carbon emissions. When the remanufactured product carbon emission is less than the new product, allocating more free carbon quota can reduce the recovery rate instead.

\section{Conclusions}

The Stackelberg game theory is applied in this article which studies the impact of the competition, carbon quotas and 


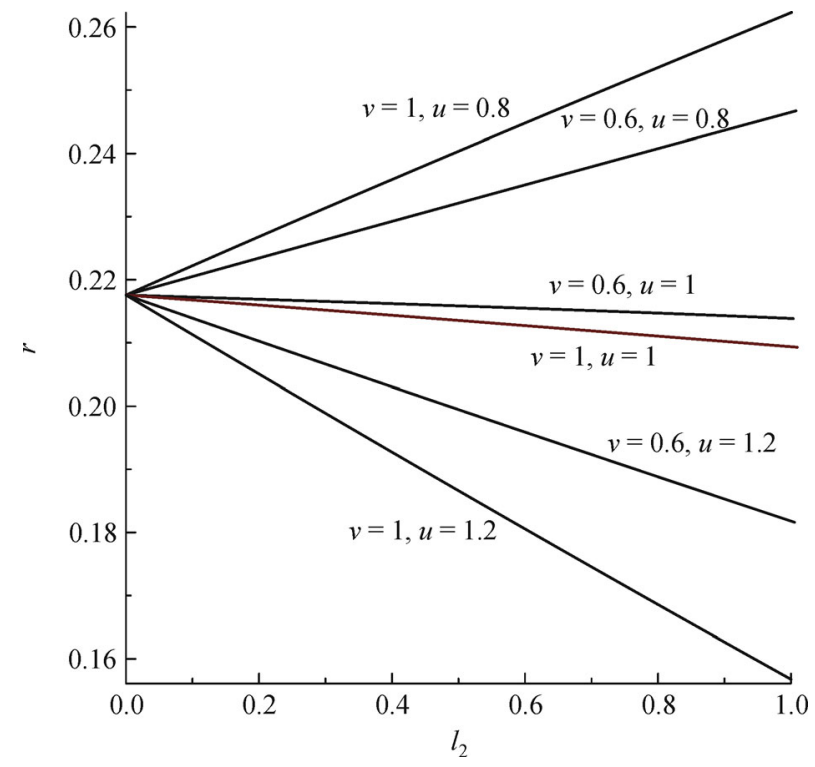

Figure 5. The impact of proportion allocation on recovery rate.

subsidies on the machinery engineering manufacturers' profit and recovery rate in a closed-loop supply chain. A model is established in this paper including two manufacturers under subsidies and carbon emission constraint. The authors reached some useful conclusions through the analysis of the model and present numerical analysis to explain some of the results obtained above. The main conclusions are as follows:

(1) Government subsidies to the third-party recycler can improve the recovery rate. Moreover, the subsidies can also raise the remanufacturer's profit and reduce the general manufacturer's profits relatively at the same time. Thus it prompts the manufacturers to remanufacture.

(2) A carbon quota charge will not necessarily lead to a decline of the recovery rate. When the remanufactured product's carbon emission is less than the new product, a carbon quota charge can improve the recovery rate.
However, the authors also considered a likely scenario that the remanufactured product carbon emission is not less than the new product, and then the carbon quota charge will cause a decline of the recovery rate if manufacturers within the industry gain the same proportion of carbon quotas. Moreover, if the remanufacturers gain more free carbon quota than general manufacturers, it will eliminate the negative impact of carbon constraint on the recovery rate. Carbon quota allocation can also adjust the profit distribution between Manufacturers 1 and 2, prompting Manufacturer 2 to invest in remanufacturing technology and to remanufacture.

(3) In order to reduce carbon emissions and improve the recovery rate simultaneously, the government can use part of the income of selling carbon quotas as subsidies to support remanufacturing research and development and application of low carbon recycling technology.

(4) The combination of subsidies and carbon quota strategies will be more flexible than any single strategy.

The authors believe the integration of carbon emission constraints and subsidies leads to an improvement to the environment, such as reducing carbon emissions that come from machinery manufacturing, improving engineering machinery utilization efficiency, etc. One of the limitations of the current study, however, is that the authors only analyzed a single-period problem based on a simple CCTmechanism. In future studies, it will be interesting to consider multiple CCT-mechanisms and multi-period problems of a closed-loop supply chain.

\section{Appendix}

For assuring the result is meaningful, the authors suppose $0 \leqslant r \leqslant 1$ then the authors have $0 \leqslant r^{\mathrm{I}}, r^{\mathrm{II}}, r^{\mathrm{III}}, r^{\mathrm{IV}} \leqslant 1$; $0 \leqslant r^{\mathrm{II}} \leqslant 1 \Rightarrow\left(\Delta-c_{0}+A\right)^{2}<32 k$.

Proof of Proportion 1:

If $l_{2}=0$ implies carbon quota is free, and substitute $l_{2}=$ 0 into Table 2, the authors have the ratio of $V_{\mathrm{m} 1}^{\mathrm{II}}$ to $V_{\mathrm{m} 2}^{\mathrm{II}}$,

$$
\frac{V_{\mathrm{m} 1}^{\mathrm{II}}}{V_{\mathrm{m} 2}^{\mathrm{II}}}=\frac{256(\varepsilon+2)^{2} k^{2}}{\left\{\left[c_{0}^{2}-2 \Delta c_{0}+\Delta^{2}-16 k+A^{2}+2 A\left(\Delta-c_{0}\right)\right](\varepsilon+1)-16 k\right\}^{2}} .
$$

Simplify the equation above, one can obtain

$$
\frac{V_{\mathrm{m} 1}^{\mathrm{II}}}{V_{\mathrm{m} 2}^{\mathrm{II}}}=\frac{256(\varepsilon+2)^{2} k^{2}}{\left\{\left[\left(\Delta-c_{0}+A\right)^{2}-32 k\right](\varepsilon+1)+16 \varepsilon k\right\}^{2}} \text {. }
$$

One can judge that $\frac{V_{\mathrm{m} 1}^{\mathrm{II}}}{V_{\mathrm{m} 2}^{\mathrm{II}}}$ is decreasing function of the independent variable $A$.

$$
r^{\mathrm{II}}=\frac{2\left(A+\Delta-c_{0}\right)(\varepsilon+2)\left(a+\varepsilon c_{\mathrm{m}}-c_{\mathrm{m}}\right)}{A\left(\varepsilon^{2}-2\right)\left(A+2 \Delta-2 c_{0}\right)+\left(\Delta^{2}-2 \Delta c_{0}+c_{0}^{2}-16 k\right) \varepsilon^{2}-2 \Delta^{2}+4 \Delta c_{0}-2 c_{0}^{2}+64 k} .
$$

One can also judge that $\frac{V_{\mathrm{m} 1}^{\mathrm{II}}}{V_{\mathrm{m} 2}^{\mathrm{II}}}$ is decreasing function of the independent variable $A$.
Proof of proportion 2:

Substitute $A=0, v=1$ into Table 2, one have 


$$
\begin{aligned}
& \frac{V_{\mathrm{m} 1}^{\mathrm{III}}}{V_{\mathrm{m} 2}^{\text {III* }}}=\frac{256(\varepsilon+2)^{2} k^{2}}{\left[l_{2}^{2} p_{\mathrm{e}}^{2} E_{\mathrm{m}}^{2}(u-1)^{2}(\varepsilon+1)-2 l_{2} p_{\mathrm{e}} E_{\mathrm{m}}(u-1)(\varepsilon+1)\left(\Delta-c_{0}\right)+\left(\Delta^{2}-2 \Delta c_{0}+c_{0}^{2}-16 k\right) \varepsilon+\Delta^{2}-2 \Delta c_{0}+c_{0}^{2}-32 k\right]^{2}} . \\
& \text { Let } Y=l_{2}^{2} p_{\mathrm{e}}^{2} E_{\mathrm{m}}^{2}(u-1)^{2}(\varepsilon+1)-2 l_{2} p_{\mathrm{e}} E_{\mathrm{m}}(u-1)(\varepsilon+1) \quad u=\frac{\Delta-c_{0}}{l_{2} p_{\mathrm{e}} E_{\mathrm{m}}}+1, Y=-\left(\Delta-c_{0}\right)^{2}(\varepsilon+1) . \\
& \left(\Delta-c_{0}\right), Y \text { is linear duality function of variable }(u-1),
\end{aligned}
$$
and $u-1=\frac{\Delta-c_{0}}{l_{2} p_{\mathrm{e}} E_{\mathrm{m}}}$ is the axis of symmetry.

The authors know $0 \leqslant u \leqslant \frac{\Delta-c_{0}}{l_{2} p_{\mathrm{e}} E_{\mathrm{m}}}$ from Table 2 , and $Y$ is decreasing in this domain of definition.

$$
\begin{gathered}
u=0, Y=l_{2}^{2} p_{\mathrm{e}}^{2} E_{\mathrm{m}}^{2}(\varepsilon+1)+2 l_{2} p_{\mathrm{e}} E_{\mathrm{m}}(\varepsilon+1)\left(\Delta-c_{0}\right), \\
u=1, Y=0,
\end{gathered}
$$

And

$$
\begin{aligned}
0 \leqslant r \leqslant 1 \Rightarrow & \left(\Delta^{2}-2 \Delta c_{0}+c_{0}^{2}-16 k\right) \varepsilon+\Delta^{2}-2 \Delta c_{0} \\
& +c_{0}^{2}-32 k<0 .
\end{aligned}
$$

Hence the authors know $0<u<1$, the income gap between Manufactures 1 and 2 gradually widens; $1<u<\frac{\Delta-c_{0}}{l_{2} p_{\mathrm{e}} E_{\mathrm{m}}}$ the income gap becomes smaller.

$$
r^{\mathrm{III}}=\frac{2\left[l_{2} p_{\mathrm{e}} E_{\mathrm{m}}\left(\varepsilon^{2}+\varepsilon-2\right)+(\varepsilon+2)\left(a+\varepsilon c_{\mathrm{m}}-c_{\mathrm{m}}\right)\right]\left[-l_{2} p_{\mathrm{e}} E_{\mathrm{m}}(u-1)+\Delta-c_{0}\right]}{l_{2} p_{\mathrm{e}} E_{\mathrm{m}}\left(\varepsilon^{2}-2\right)(u-1)\left(l_{2} p_{\mathrm{e}} E_{\mathrm{m}}(u-1)-2 \Delta+2 c_{0}\right)+\left(\Delta^{2}-2 \Delta c_{0}+c_{0}^{2}-16 k\right) \varepsilon^{2}-2 \Delta^{2}+4 \Delta c_{0}-2 c_{0}^{2}+64 k} .
$$

The judge process is similar to the above.

Proof of Proportion 3:

Substitute $A=0, u=1$ into Table 2 .
Assume $v=1$, it means the government allocates the same proportion of carbon quotas on gratuitously. The authors have

$$
\begin{gathered}
r^{\mathrm{III**}}=\frac{2\left[l_{2} p_{\mathrm{e}} E_{\mathrm{m}}\left(\varepsilon^{2}+\varepsilon-2\right)+(\varepsilon+2)\left(a+\varepsilon c_{\mathrm{m}}-c_{\mathrm{m}}\right)\right]\left(\Delta-c_{0}\right)}{\left(\Delta^{2}-2 \Delta c_{0}+c_{0}^{2}-16 k\right) \varepsilon^{2}-2 c_{0}^{2}-2 \Delta^{2}+4 \Delta c_{0}+64 k}, \\
V_{\mathrm{m} 1}^{\mathrm{II} 1 *}=\frac{128\left[l_{2} p_{\mathrm{e}} E_{\mathrm{m}}\left(\varepsilon^{2}+\varepsilon-2\right)+(\varepsilon+2)\left(\varepsilon c_{\mathrm{m}}+a-c_{\mathrm{m}}\right)\right]^{2} k^{2}}{\left[\left(\Delta^{2}-2 \Delta c_{0}+c_{0}^{2}-16 k\right) \varepsilon^{2}-2 \Delta^{2}+4 \Delta c_{0}-2 c_{0}^{2}+64 k\right]^{2}}, \\
V_{\mathrm{m} 2}^{\mathrm{II} * *}=\frac{1}{2} \frac{\left[\left(-\Delta^{2}+2 \Delta c_{0}-c_{0}^{2}+16 k\right) \varepsilon-\Delta^{2}+2 \Delta c_{0}-c_{0}^{2}+32 k\right]^{2}\left[l_{2} p_{\mathrm{e}} E_{\mathrm{m}}(\varepsilon-1)+\varepsilon c_{\mathrm{m}}+a-c_{\mathrm{m}}\right]^{2}}{\left[\left(\Delta^{2}-2 \Delta c_{0}+c_{0}^{2}-16 k\right) \varepsilon^{2}-2 \Delta^{2}+4 \Delta c_{0}-2 c_{0}^{2}+64 k\right]^{2}}, \\
\frac{V_{\mathrm{m} 1}^{\mathrm{III*}}}{V_{\mathrm{m} 2}^{\mathrm{III*}}}=\frac{256(\varepsilon+2)^{2} k^{2}}{\left(-\Delta^{2} \varepsilon+2 \Delta \varepsilon c_{0}-\varepsilon c_{0}^{2}-\Delta^{2}+2 \Delta c_{0}+16 \varepsilon k-c_{0}^{2}-32 k\right)^{2}} .
\end{gathered}
$$

Assume $0<v<1$, it means the government allocates more free carbon quotas to Manufacture 1 . The authors have

$$
\frac{V_{\mathrm{m} 1}^{\mathrm{III**}}}{V_{\mathrm{m} 2}^{\mathrm{III**}}}=\frac{256 k^{2}\left[l_{2} p_{\mathrm{e}} E_{\mathrm{m}} v\left(\varepsilon^{2}-2\right)+c_{\mathrm{m}} \varepsilon^{2}+\left(l_{2} p_{\mathrm{e}} E_{\mathrm{m}}+a+c_{\mathrm{m}}\right) \varepsilon-2 c_{\mathrm{m}}+2 a\right]^{2}}{\left[l_{2} p_{\mathrm{e}} E_{\mathrm{m}}\left(-16 k \varepsilon v+N \varepsilon^{2}-N+16 k\right)+(N \varepsilon+N-16 k)\left(\varepsilon c_{\mathrm{m}}+a-c_{\mathrm{m}}\right)\right]^{2}},
$$

where $N=\Delta^{2}-2 \Delta c_{0}+c_{0}^{2}-16 k$.

One can judge $\frac{V_{\mathrm{m} 1}^{\mathrm{III**}}}{V_{\mathrm{m} 2}^{\mathrm{II}}}$ is a decreasing function of the independent variable $v$.
Acknowledgements The authors thank the editor and reviewers for their detailed comments and many valuable suggestions that have significantly improved the quality of this paper. This research was supported by the National Natural Science Foundation of China (70921001, 71431006, 71271216), by the Education Ministry Social Science of China (13JZD016). 


\section{References}

Amezquita, T., Hammond, R., Salazar, M., \& Bras, B. (1995). Characterizing the remanufacturability of engineering systems. In: Proceedings of 1995 ASME Advances in Design Automation Conference. DE-82(1), 271-278.

Bird, L. A., Holt, E., \& Levenstein Carroll, G. (2008). Implications of carbon cap-and-trade for US voluntary renewable energy markets. Energy Policy, 36(6), 2063-2073.

Cason, T. N. (2003). Buyer liability and voluntary inspections in international greenhouse gas emissions trading: A laboratory study. Environmental and Resource Economics, 25(1), 101-127.

Chang, X., Xia, H., Zhu, H., Fan, T., \& Zhao, H. (2015). Production decisions in a hybrid manufacturing-remanufacturing system with carbon cap and trade mechanism. International Journal of Production Economics, 162, 160-173.

Chen, X., \& Zhou, Z. (2014). Promote the engineering of ecological civilization construction by building "resource-conserving and environment-friendly society". Frontiers of Engineering Management, 1(1), 83-88.

Debo, L. G., Toktay, L. B., \& Wassenhove, L. N. V. (2005). Market segmentation and product technology selection for remanufacturable products. Management Science, 51(8), 1193-1205.

Blass, V.(2012). Closed-loop supply chains: New developments to improve the sustainability of business practices. Journal of Industrial Ecology, 16(2), 285.

Ferguson, M. E., \& Souza, G. C. (2010). Closed-loop Supply Chains: New Developments to Improve the Sustainability of Business Practices. Boca Raton: CRC Press.

Ferrer, G., \& Swaminathan, J. M. (2006). Managing new and remanufactured products. Management Science, 52(1), 15-26.

Gao, J., Hou, L., Wang, H., \& Han, H. (2015). Regularity research on revenue fluctuation analysis of closed-loop supply chain considered carbon emissions. Chinese Journal of Mechanical Engineering, 51 (2), 190-197.

Giutini, R., \& Gaudette, K. (2003). Remanufacturing: The next great opportunity for boosting us productivity. Business Horizons, 46(6), $41-48$.

Guan, Q., Zhou, G., \& Cao, J. (2009). Government constrained decision making model in recycling and remanufacturing closed-loop supply chain. Industrial Engineering Journal, 12(5), 40-44.
Guide, V. D. R. Jr, \& Van Wassenhove, L. N. (2006). Closed-loop supply chains: An introduction to the feature issue (Part 1). Production and Operations Management, 15(3), 345-350.

Guide, V. D. R. Jr, \& Van Wassenhove, L. N. (2009). The evolution of closed-loop supply chain research. Operations Research, 57(1), 10 18.

Heese, H. S., Cattani, K., Ferrer, G., Gilland, W., \& Roth, A. V. (2005). Competitive advantage through take-back of used products. European Journal of Operational Research, 164(1), 143-157.

Li, J., Du, W., Yang, F., \& Hua, G. (2014). The carbon subsidy analysis in remanufacturing closed-loop supply chain. Sustainability, 6(6), 3861-3877.

Majumder, P., \& Groenevelt, H. (2001). Competition in remanufacturing. Production and Operations Management, 10(2), 125-141.

Mitra, S., \& Webster, S. (2008). Competition in remanufacturing and the effects of government subsidies. International Journal of Production Economics, 111(2), 287-298.

Montgomery, W. D. (1972). Markets in licenses and efficient pollution control programs. Journal of Economic Theory, 5(3), 395-418.

Savaskan, R. C., Bhattacharya, S., \& Van Wassenhove, L. N. (2004). Closed-loop supply chain models with product remanufacturing. Management Sciences, 50(2), 239-252.

Stavins, R. N. (2008). A meaningful U.S. cap-and-trade system to address climate change. SSM Electronic Journal, 32(2008.82), 293371.

Sutherland, J. W., Adler, D. P., Haapala, K. R., \& Kumar, V. (2008). A comparison of manufacturing and remanufacturing energy intensities with application to diesel engine production. Manufacturing Technology, 57(1), 5-8.

Wang, W., \& Da, Q. (2011). The decision and coordination under the premium and penalty mechanism for closed-loop supply chain. Chinese Journal of Management Science, 19(1), 36-41 (in Chinese).

Xiong, Z., Huang, D., \& Xiong, Y. (2011). On the closed-loop supply chain modes of product remanufacturing with government reimbursement. Industrial Engineering Journal, 14, 1-5.

Zeng, G., \& Wan, Z. (2010). Literature review on carbon emissions trading theory and application research. Chinese Review of Financial Studies, (02), 54-67 (in Chinese).

Zheng, J., Zheng, C., Chen, P., \& Lu, C. Y. (2014). An evaluation model for the coordinated development of a circular economy in China and its application to energy-intensive industries. Frontiers of Engineering Management, 1(4), 364-371. 